\title{
ASSESSMENT OF FINAL SHADE AND TRANSLUCENCY OF TWO MONOLITHIC ZIRCONIA VERSUS VENEERED ZIRCONIA ON A DARK SUBSTRATE. AN INVITRO STUDY
}

\author{
Karim Aboubakr * and Noha Adel Elkhodary*
}

\begin{abstract}
Statement of the problem: The ability of all ceramic restoration to mask an underlying discolored substrate is important to obtain adequate esthetics. There are different types of zirconia ceramics and their optical properties has not yet been addressed.
\end{abstract}

Objectives: The aim of this study was to assess the final shade and translucency of two monolithic zirconia versus veneered zirconia on a dark substrate.

Materials and methods: 15 square shaped A2 zirconia specimens were cut using cutting machine (Isomet; Buehler Ltda.). Specimens were divided into 3 groups according to the type of zirconia (5 mol \% Y-ZP zirconia, 3 mol\% Y-TZP zirconia and veneered zirconia) their CIE L*, a* and $\mathrm{b}^{*}$ values were measured using a spectrophotometer against white and black backgrounds at the center of the specimens in order to determine the translucency parameter (TP). Then 15 composite discs (Artiste ${ }^{\mathrm{TM}}$, Pentron, USA) of shade C3 were fabricated. Zirconia specimens were placed on the composite background without any intervening material in-between then CIE L*, a* and $b^{*}$ values were measured and color difference $\Delta \mathrm{E}$ value was calculated. To determine the masking ability, perceptibility threshold was assumed as $\Delta \mathrm{E}=3.7$.

Results: There was a statistically significant difference between mean TP values and mean $\Delta \mathrm{E}$ values in the three groups where Cubic Zirconia showed statistically significant highest mean TP (10.97), Tetragonal Zirconia showed statistically significant lower mean TP (8.7) and Veneered Zirconia showed statistically significant lowest mean TP (7.72). As for color change $\Delta \mathrm{E}$, Cubic Zirconia showed statistically significant highest mean $\Delta \mathrm{E}$ (9.04), Tetragonal Zirconia showed statistically significant lower mean value (7.06) and Veneered Zirconia showed statistically significant lowest mean $\Delta \mathrm{E}(6.26)$.

Conclusions: Masking ability and translucency was affected by the type of the zirconia used due to difference in their composition. Neither the two monolithic zirconia nor the veneered one were able to mask the color of the underlying substrate. Increasing the yttria content to $5 \mathrm{~mol} \%$ increased the content of nonbirefringent (isotropic) cubic phase which was found to increase the translucency parameter of the zirconia.

KEYWORDS: Tetragonal zirconia, cubic zirconia, color change, translucency parameter.

\footnotetext{
* Lecturer of Fixed Prosthodontics Department Faculty of Dentistry, Cairo University, Egypt.
} 


\section{INTRODUCTION}

Obtaining a natural esthetic appearance with a metal ceramic restoration has become challenging as a result of the metal coping not allowing light transmission which resulted in a shift to use a nonmetallic restoration. ${ }^{(1,2)}$ Metal free restorations are now popular due to their biocompatibility and the high esthetic properties. The introduction of digital dentistry and the use of CAD/CAM technology allowed the use of yttria stabilized zirconia (Y-TZP) for prosthesis fabrication since about two decades. ${ }^{(3,4)}$ It has been claimed that zirconia is the toughest and strongest material that have been used in dentistry however its opacity remains a major drawback especially when replacing anterior restoration. Trying to solve this problem will require additional tooth preparation in order to allow for space to veneer the zirconia with a highly esthetic glass ceramic. However also problems as veneer delamination and chipping still remain a major concern. ${ }^{(5-8)}$

Y-TZP is characterized by being an opaque material as a result of the non-cubic phase with inherent birefringence which results in light scattering. In order to improve translucency; 3 Y-TZP was refined by decreasing the alumina concentration and removing porosity by sintering at high temperature ${ }^{(9)}$; however it's esthetic properties was found to still limit its use to the posterior region. Thus a new generation of monolithic zirconia was introduced by adding some transparent phase in order to decrease opacity. This was done by increasing the yttria content to produce $4 \mathrm{~mol} \%$ or $5 \mathrm{~mol} \%$ (4Y-PSZ, 5 Y-PSZ) partially stabilized zirconia with high content of nonbirefringent (isotropic) cubic phase. This was found to enhance the translucency parameter of the zirconia but on the other hand decreased the strength properties because of the inability of the cubic phase to undergo stress induced transformation. ${ }^{(10)}$

Monolithic zirconia restorations showed difficulties in term of esthetics and is affected by the optical properties and the shade determined by manufacturer processes in addition to the laboratory procedure and some clinical factors as the features of the zirconia restoration, cement and the color of the background. ${ }^{(11-15)}$

In some cases, as teeth with deep discoloration, metallic core, implant titanium abutment or even a colored substrate, a translucent ceramic material may not be able to mask the underlying discoloration. ${ }^{(16,17)}$ Thus in such cases a ceramic material able to mask the discolored background should be used in order to maintain adequate esthetic outcome. To evaluate the masking ability of a restoration $\Delta \mathrm{E}$ color difference have to be measured in CIE lab system in which $\mathrm{L}^{*}$ represents the lightness, $\mathrm{a}^{*}$ represents red/green value and $\mathrm{b}^{*}$ represents yellow/blue value using spectrophotometer in which $\Delta \mathrm{E}^{*}=\left[\left(\mathrm{L}^{*}{ }_{2}-\mathrm{L}^{*}{ }_{1}\right)^{2}+\right.$ $\left.\left.\left(\mathrm{a}_{2}{ }_{2}-\mathrm{a}{ }_{1}\right)_{1}\right)^{2}+\left(\mathrm{b}_{2}{ }_{2}-\mathrm{b}^{*}{ }_{1}\right)^{2}\right]^{1 / 2} \cdot{ }^{(18)}$

Perceptibility is to recognize color difference between objects with human's eye while acceptability is the acceptable color difference in shade match. Different studies have shown different perceptible and acceptable limits for $\Delta \mathrm{E} \cdot{ }^{(19-23)}$ However it has been found that the acceptable threshold is more than the perceptional one and that if the $\Delta \mathrm{E}$ value was found to be more than the threshold thus a color difference can be detected. ${ }^{(18,20)}$ In literature the perceptional threshold was claimed to range from $1-5.5 \Delta \mathrm{E}$ units. ${ }^{(21-23)}$ Some studies have shown that 2.6, 3.3 and $3.7 \Delta \mathrm{E}$ units are clinically acceptable values ${ }^{(24-26)}$, while other studies showed different values.$^{(27,28)}$ It has been found that $\Delta \mathrm{E}$ value less than 5.5 showed a clinically acceptable color difference while that less than 2.6 showed ideal color difference that cannot be detected even by a clinician. ${ }^{(20,29)}$

Translucency parameter measures the translucency of a material which is the state between complete opacity and transparency $(30,31)$ and can be defined as the difference in color of a given thickness of a material in contact with ideal 
black and white backgrounds. ${ }^{(32)}$ Studies have found that there are different factors that can affect the optical properties of zirconia restorations which include; type and amount of the additives, sintering conditions, temperature and heating methods, light scattering which is affected by the inclusion of pores ${ }^{(33-38)}$, thickness of the material, variation in structure and composition in addition to the color of the substrate which also affect the final esthetic outcome of a restoration. ${ }^{(39,40)}$ The translucency parameter of zirconia restorations has been found to range from 5.5 to $15.1{ }^{(41)}$

Highly translucent zirconia can be used for both anterior and posterior restorations however information about these materials are limited, thus the aim of this study was to assess the final shade and translucency of two monolithic zirconia versus veneered zirconia on a dark substrate. The null hypothesis was that both types of translucent monolithic zirconia and the veneered zirconia will be able to mask the color of the dark substrate.

\section{MATERIALS AND METHODS:}

Partially sintered zirconia blocks shade A2 were used in this study as tetragonal monolithic zirconia (3 mol\% Y-TZP) (BruxZir®, Glidewell Laboratories, USA), cubic zirconia (5 mol \% Y-ZP) (BruxZir® Anterior, Glidewell Laboratories, USA) and veneered zirconia (BruxZir ${ }^{\circledR}$, Glidewell Laboratories, USA). Zirconia blocks were cut using diamond saw (Isomet 4000, Buehler Ltda) creating fifteen squared shaped samples.

Samples were classified into 3 groups $(n=5 /$ group) according to type of zirconia used. The samples of monolithic zirconia groups were sectioned transversely into plates with definite thickness of $1.5 \mathrm{~mm}$, while those of the veneered zirconia were cut into $1 \mathrm{~mm}$ thickness; digital caliper was used to check and confirm sample thickness. Sintering was completed in high temperature furnace (Nabertherm Industrial Furnaces Co. Ltd., Germany) following the manufacturer's instructions and final glazing cycle was done using Programat P310 furnace (Ivoclar Vivadent, Schaan, Liechtenstein).

For the veneered zirconia special rectangular mold was used with $1.6 \mathrm{~mm}$ thickness to accommodate the zirconia sample and allow for porcelain veneering for $0.6 \mathrm{~mm}$. Increasing thickness of mold allow for extra thickness of veneering to compensate for firing shrinkage. Veneering was done using using IPS e-max ceram (fluorapetite glass ceramic) (Ivoclar Vivadent, Schaan, Liechtenstein). Zirconia specimens were first cleaned from any dirt and then mixing of IPS e.max Zirliner with its corresponding liquid was done until we obtained a creamy consistency and then it was applied on the zirconia and fired in the porcelain furnace Programat P310 furnace (Ivoclar Vivadent, Schaan, Liechtenstein). IPS e.max ceram (Ivoclar Vivadent, Schaan, Liechtenstein) was mixed with its liquid and then applied in increments over the zirconia and properly condensed to completely fill the space over the zirconia. Firing was performed using Programat P310 furnace following the manufacturer's instructions. Rechecking of the samples thickness were made using digital caliper. Glazing was then done following manufacturer's recommendations

\section{Background construction:}

A mold former was constructed for obtaining the fifteen dark composite samples (shade C3) of $4 \mathrm{~mm}$ thickness (Artiste ${ }^{\mathrm{TM}}$ composite shade C3, Pentron, USA). The mold was assembled and was placed over glass slab. Composite was packed inside the mold's rectangular opening then covered with a matrix to avoid inhibition of polymerization of composite. The samples were covered with glass slab in order to obtain smooth surface free from air bubbles. Light curing was done using Woodpecker DTE Light Cure (Woodpecker, China) with wavelength of $\left(800 \mathrm{~mW} / \mathrm{cm}-1600 \mathrm{~mW} / \mathrm{cm}^{2}\right)$ and light intensity $\left(1200 \mathrm{~mW} / \mathrm{cm}^{2}\right)$ curing was made for 40 secs and after removal of glass slab further curing was made 
for 20 secs from all directions. Composite plates were then polished with silicon polishers and Soflex discs. Composite samples were checked with digital caliper to ensure adequate thickness.

Samples were then numbered from 1 to 5 for each group of zirconia and for the composite background and then divided randomly by www.random.org at allocation ratio 1:1 and sealed in a closed envelope to avoid selection bias.

\section{Color difference measurements:}

After preparation of the samples and background, Spectrophotometer (Cary 5000 Agilent Technologies, USA) was used to measure the color difference with changing background from white to the dark composite background using standard light source D65. Each specimen was in the specimen holder inside the black box which serve to eliminate the effect of external light. Specimens were always placed in the center of display screen.

The spectrophotometric measurement was recorded as means $\mathrm{L}^{*} \mathrm{a} * \mathrm{~b} *$ values for each specimen. Where $\mathrm{L}^{*}$ is a measure of the Lightness of an object, $a^{*}$ is a measure of redness or greenness and $b^{*}$ is a measure of yellowness or blueness. Then color change values $(\Delta \mathrm{E})$ were calculated through the following formula:

$$
\Delta \mathrm{E}=\left[\left(\mathrm{L}^{*}{ }_{\mathrm{a}}-\mathrm{L}_{\mathrm{b}}^{*}\right)^{2}+\left(\mathrm{a}^{*}{ }_{\mathrm{a}}-\mathrm{a}^{*}{ }_{\mathrm{b}}\right)^{2}+\left(\mathrm{b}^{*}{ }_{\mathrm{a}}-\mathrm{b}^{*}{ }_{\mathrm{b}}\right)^{2}\right]^{1 / 2}
$$

Where $\Delta \mathrm{E}=$ change in color

$\mathrm{a}=$ ceramic with white background .

$$
\begin{aligned}
& \mathrm{b}=\text { ceramic with composite (C3) dark } \\
& \text { background. }
\end{aligned}
$$

In this study perceptional threshold was hypothesized to be $\Delta \mathrm{E}=3.7$

Translucency parameter (TP) was measured for each type of zirconia material using spectrophotometer with ceramic samples over white and black background.
$\mathrm{TP}=\left[\left(\mathrm{L}^{*}{ }_{\mathrm{B}}-\mathrm{L}^{*}{ }_{\mathrm{W}}\right)^{2}+\left(\mathrm{a}^{*}{ }_{\mathrm{B}}-\mathrm{a}^{*}{ }_{\mathrm{W}}\right)^{2}+\left(\mathrm{b}^{*}{ }_{\mathrm{B}}-\mathrm{b}^{*}{ }_{\mathrm{W}}\right)^{2}\right]^{1 / 2}$

Where TP is the translucency parameter.

$$
\begin{aligned}
& \mathrm{W}=\text { white background } . \\
& \mathrm{B}=\text { black background } .
\end{aligned}
$$

Both the statistician and the assessors were blinded in order to minimize the risk of bias.

\section{RESULTS}

Numerical data were explored for normality by checking the distribution of data and using tests of normality (Kolmogorov-Smirnov and ShapiroWilk tests). All data showed normal (parametric) distribution. Data were presented as mean and standard deviation (SD) values. One-way ANOVA test was used to compare between the three groups. Bonferroni's post-hoc test was used for pair-wise comparisons when ANOVA test is significant. The significance level was set at $\mathrm{P} \leq 0.05$. Statistical analysis was performed with IBM SPSS Statistics for Windows, Version 23.0. Armonk, NY: IBM Corp.

Color change $(\Delta \mathrm{E})$ : There was a statistically significant difference between mean $\Delta \mathrm{E}$ values in the three groups $(P$-value $<0.001$, Effect size $=$ 0.901). Pair-wise comparisons between the groups revealed that Cubic Zirconia showed the statistically significantly highest mean $\Delta \mathrm{E}$. Tetragonal Zirconia showed statistically significant lower mean value. Veneered Zirconia showed the statistically significant lowest mean $\Delta \mathrm{E}$.

$\Delta \mathbf{L}:$ There was a statistically significant difference between mean $\Delta \mathrm{L}$ values in the three groups $(P$-value $<0.001$, Effect size $=0.799)$. Pair-wise comparisons between the groups revealed that $\mathrm{Cu}-$ bic Zirconia showed statistically significant highest mean $\Delta \mathrm{L}$. There was no statistically significant difference between Tetragonal Zirconia and veneered Zirconia; both showed statistically significant lowest mean $\Delta \mathrm{L}$. 
$\Delta$ a: There was a statistically significant difference between mean $\Delta$ a values in the three groups $(P$-value $=0.003$, Effect size $=0.628)$. Pair-wise comparisons between the groups revealed that $\mathrm{Cu}-$ bic Zirconia showed statistically significant highest mean $\Delta$ a. Tetragonal Zirconia showed statistically significant lower mean value. Veneered Zirconia showed statistically significant lowest mean $\Delta \mathrm{a}$.

$\Delta \mathbf{b}$ : There was a statistically significant difference between mean $\Delta \mathrm{b}$ values in the three groups $(P$-value $<0.001$, Effect size $=0.872)$. Pair-wise comparisons between the groups revealed that $\mathrm{Cu}-$ bic Zirconia showed the statistically significantly highest mean $\Delta \mathrm{b}$. Tetragonal Zirconia showed statistically significantly lower mean value. Veneered Zirconia showed the statistically significant lowest mean $\Delta b$.

Translucency parameter (TP): There was a statistically significant difference between mean TP values in the three groups ( $P$-value $<0.001$, Effect size $=0.989)$. Pair-wise comparisons between the groups revealed that Cubic Zirconia showed statistically significant highest mean TP. Tetragonal Zirconia showed statistically significant lower mean value. Veneered Zirconia showed statistically significant lowest mean TP.

TABLE (1) Mean, standard deviation (SD) values and results of one-way ANOVA test for comparison between the three groups

\begin{tabular}{|c|c|c|c|c|c|}
\hline \multirow[t]{2}{*}{ Measurement } & $\begin{array}{l}\text { Cubic Zirconia } \\
\qquad(\mathrm{n}=5)\end{array}$ & $\begin{array}{l}\text { Tetragonal Zirconia } \\
\qquad(\mathrm{n}=5)\end{array}$ & $\begin{array}{l}\text { Veneered Zirconia } \\
\qquad(\mathrm{n}=5)\end{array}$ & \multirow{2}{*}{$P$-value } & \multirow{2}{*}{$\begin{array}{c}\text { Effect size (Eta } \\
\text { Squared) }\end{array}$} \\
\hline & Mean (SD) & Mean (SD) & Mean (SD) & & \\
\hline $\mathrm{TP}$ & $10.97(0.19)^{\mathrm{A}}$ & $8.7(0.14)^{\text {в }}$ & $7.72(0.14)^{\mathrm{C}}$ & $<0.001^{*}$ & 0.989 \\
\hline$\Delta \mathrm{E}$ & $9.04(0.52)^{\mathrm{A}}$ & $7.06(0.42)^{\mathrm{B}}$ & $6.26(0.34)^{\mathrm{C}}$ & $<0.001 *$ & 0.901 \\
\hline$\Delta \mathrm{L}$ & $8.22(0.69)^{\mathrm{A}}$ & $6.52(0.47)^{\text {В }}$ & $6.08(0.32)^{\text {В }}$ & $<0.001 *$ & 0.799 \\
\hline$\Delta \mathrm{a}$ & $1.07(0.21)^{\mathrm{A}}$ & $0.75(0.15)^{\mathrm{B}}$ & $0.48(0.15)^{\mathrm{C}}$ & $0.003 *$ & 0.628 \\
\hline$\Delta \mathrm{b}$ & $3.56(0.52)^{\mathrm{A}}$ & $2.59(0.15)^{\text {в }}$ & $1.38(0.38)^{\mathrm{C}}$ & $<0.001 *$ & 0.872 \\
\hline
\end{tabular}

*: Significant at $P \leq 0.05$, Different superscripts in the same row indicate statistically significant differences between groups

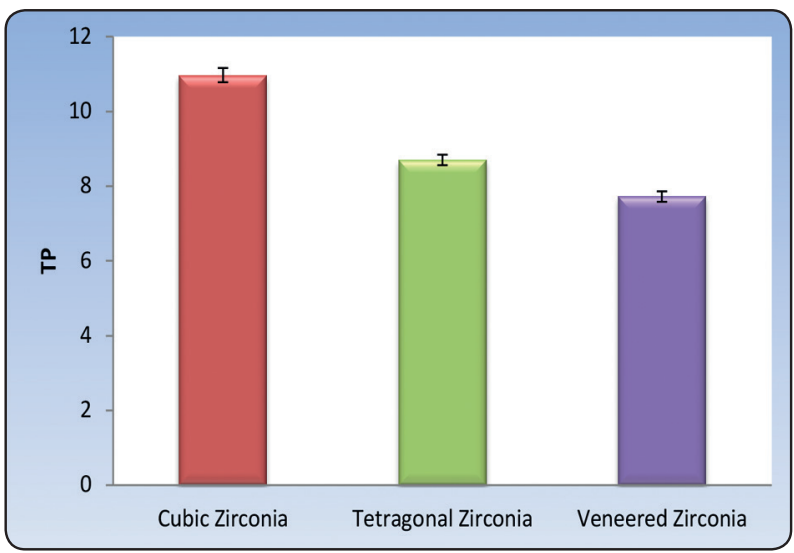

Fig. (1) Bar chart representing mean and standard deviation values for TP in the different groups

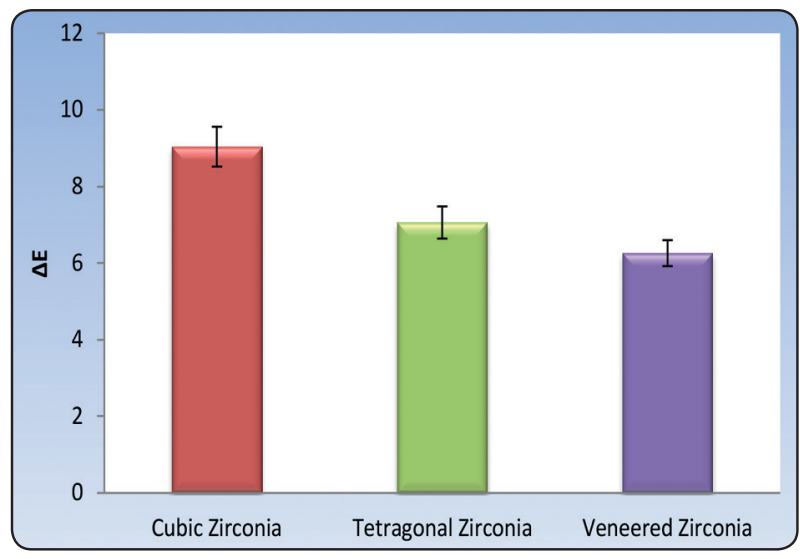

Fig. (2) Bar chart representing mean and standard deviation values for $\Delta \mathrm{E}$ in the different groups 


\section{DISCUSSION}

This study aimed to determine the effect of using two types of monolithic zirconia versus veneered zirconia over dark back ground on the final shade and translucency parameter. The results showed that neither the monolithic nor the veneered zirconia were able to mask the color of the dark substrate, hence the null hypothesis was rejected.

Since esthetics had become the primary patient concern in addition in aiming to avoid chipping of porcelain veneer and to speed up the dental procedure, CAD/CAM monolithic ceramic blocks have been widely used nowadays. ${ }^{(41)}$ Zirconia has been found to be one of the most successful dental restorations, however their main drawback was the low esthetic performance which results from the inability to obtain a satisfactory and adequate transparency. ${ }^{(42.43)}$ It has been found that in order to make the zirconia restoration more translucent and esthetic; scattering of light has to be eliminated. One of the factors that have been found to affect the translucency of the zirconia was the yttria content. Increasing the yttria content (4-5 mol\%) in partially stabilized zirconia increased the translucency as a result of the increased amount of nonbirefringent cubic phase $(>25-50 \%)$ which is characterized by being isotropic which is unlike the anisotropic tetragonal grains as it decreases the scattering at the grain boundaries, thus resulting in a material with high translucency. ${ }^{(44-46)}$

In this study it was found that there was a statistically significant difference between mean $\mathrm{TP}$ values in the three groups where cubic Zirconia showed the statistically significantly highest mean TP, tetragonal Zirconia showed statistically significantly lower mean value while veneered Zirconia showed the statistically significantly lowest mean TP. Thus increasing the yttria content tend to increase the translucency and this was in accordance with a study done by Cho et al in 2020 . (47) This was attributed to the larger cubic grains than the tetragonal one, this was also confirmed by other studies which stated that the larger the grain size of the zirconia the more it will be transparent. ${ }^{(48,49)}$

The choice of an esthetic translucent ceramic restoration to produce an ideal clinical color match is a crucial element especially over a darkened substrate as it may affect the final shade of the ceramic restorations. ${ }^{(50,51)}$ A scientific standardized spectrophotometer was used in this study for measuring both the translucency parameter and the color match for each group. In order to determine a color difference and interpret results; $\Delta \mathrm{E}$ threshold value is necessary, in studies acceptability and perceptibility thresholds showed different values and also sites and observers can make differences in both thresholds. ${ }^{(52)}$ Three intervals have been suggested for the threshold where $\Delta \mathrm{E}<1$ shows color difference that can't be detected by human's eyes, $\Delta \mathrm{E}<3.3$ shows a clinically acceptable color differences which can only be detectable by a skilled operator and $\Delta \mathrm{E}>3.3$ shows difference that can be noticed by patients and is clinically unacceptable. ${ }^{(18,19)}$ In this study acceptable threshold value used was $\Delta \mathrm{E}=3.7$ based on a systematic study done by Khashayar et al in $2014^{(53)}$ who found that $35 \%$ of studies in dentistry used $\Delta \mathrm{E}=3.7$ as an acceptable threshold value as $50 \%$ of the observers accepted the color differences at this value.

Results of the current study showed that $\Delta \mathrm{L}$ which is the measure of lightness showed statistically significant higher mean value for the cubic zirconia while the tetragonal and veneered one showed statistically significant lower mean value. This showed that the structure of the zirconia had an impact on its lightness and this can be attributed to the difference in their optical properties. An increase in the $\Delta \mathrm{L}$ will result in a color shift towards white and this was found with the cubic zirconia. ${ }^{(54)}$

As for $\Delta \mathrm{a}$ and $\Delta \mathrm{b}$ there was statistically significant difference among the three groups; the cubic zirconia showed statistically significantly 
highest mean $\Delta \mathrm{a}$, while tetragonal zirconia showed statistically significantly lower mean value and the veneered Zirconia showed the statistically significantly lowest mean $\Delta$ a.

Results also showed that neither the two monolithic zirconia nor the veneered one were able to mask the dark substrate, where cubic zirconia showed mean $\Delta \mathrm{E}=9.04$ and the tetragonal one showed mean $\Delta \mathrm{E}=7.06$ while the veneered zirconia showed mean $\Delta \mathrm{E}=6.26$. All values were above the clinically acceptable threshold. Thus the color of zirconia restorations were affected by the underling background; this was in agreement with a study done by Tabatabaian et al in $2017^{(55)}$ which stated that the masking ability of zirconia was dependent on the underlying substrate and that the tested zirconia could not mask different shades of composite substrate. Also Suputtamongkol et al in $2013^{(56)}$ stated that the substrate color whether a composite core or metal affected the final color of the zirconia restorations.

Also a study done by Cho et al in $2020^{(47)}$ who studied the translucency and the masking ability of zirconia with different yttria content $3 \mathrm{~mol} \%$, $4 \mathrm{~mol} \%$ and $5 \mathrm{~mol} \%$ and different thickness over different substrates found that monolithic zirconia could not mask discolored dentin neither at 0.8 nor $1.5 \mathrm{~mm}$ thickness.

\section{Limitations of this study}

Limitations of this study that it was related to a single thickness and shade of monolithic zirconia and also eliminated the effect of cement which might have an effect on the final shade.

\section{Recommendations}

Thus further studies are required for different monolithic zirconia with different thicknesses and cement types.

\section{CONCLUSIONS}

Within the limitations of this study the following can be concluded:

1. Masking ability and translucency was affected by the type of the zirconia used due to difference in their composition.

2. Neither the two monolithic zirconia nor the veneered one were able to mask the color of the underlying substrate.

3. Increasing the yttria content to $5 \mathrm{~mol} \%$ increased the content of nonbirefringent (isotropic) cubic phase which was found to increase the translucency parameter of the zirconia.

\section{REFERENCES}

1. Jeong ID, Bae SY, Kim DY, Kim JH, Kim WC. Translucency of zirconia-based pressable ceramics with different core and veneer thicknesses. J Prosthet Dent. 2016; 115:768-72. doi: 10.1016/j.prosdent.2015.11.003

2. Harada K, Raigrodski AJ, Chung KH, Flinn BD, Dogan S, Mancl LA. A comparative evaluation of the translucency of zirconias and lithium disilicate for monolithic restorations. J Prosthet Dent. 2016; 116:257-63. doi: 10.1016/j. prosdent.2015.11.019.

3. Denry I, Kelly JR. Emerging ceramic-based materials for dentistry. J Dent Res 2014;93:1235-42.

4. Bayne SC, Ferracane JL, Marshall GW, Marshall SJ, van Noort R. The evolution of dental materials over the past century: silver and gold to tooth color and beyond. J Dent Res 2019;98:257-65.

5. Larsson C, Vult Von Steyern P. Implant-supported fullarch zirconia-based mandibular fixed dental prostheses. Eight-year results from a clinical pilot study. Acta Odontol Scand 2012;71:1118-22.

6. Ortorp A, Kihl ML, Carlsson GE. A 5-year retrospective study of survival of zirconia single crowns fitted in a private clinical setting. J Dent 2012;40:527-30.

7. Schmitter M, Mussotter K, Rammelsberg P, Gabbert O, Ohlmann B. Clinical performance of long-span zirconia frameworks for fixed dental prostheses: 5-year results. J Oral Rehabil 2012;39:552-7. 
8. Zhang Y, Kim JW. Graded zirconia glass for resistance to veneer fracture. J Dent Res 2010;89:1057-62.

9. Tong H, Tanaka CB, Kaiser MR, Zhang Y. Characterization of three commercial Y-TZP ceramics produced for their high translucency. Ceram Int. 2016;42(1 Pt B):1077-1085.

10. Zhang F, Inokoshi M, Batuk M, Hadermann J, Naert I, VanMeerbeek B, Vleugels J. Strength, toughness and aging stability of highly-translucent Y-TZP ceramics for dental restorations. Dent Mater. 2016;32:e327-e337.

11. Basso GR, Kodama AB, Pimentel AH, et al. Masking colored substrates using monolithic and bilayer CAD-CAM ceramic structures. Oper Dent 2017;42:387-395

12. Sagirkaya E, Arikan S, Sadik B, et al. A randomized, prospective, open-ended clinical trial of zirconia fixed partial dentures on teeth and implants: interim results. Int $\mathrm{J}$ Prosthodont 2012;25:221-231.

13. Kurbad A. Microveneering technique for esthetic enhancement of monolithic zirconia restorations. Int $\mathrm{J}$ Comput Dent 2016;19:165-178.

14. Raut A, Rao PL, Ravindranath T. Zirconium for esthetic rehabilitation: an overview. Indian J Dent Res 2011;22:140143.

15. Barao VA, Gennari-Filho H, Goiato MC, et al. Factors to achieve aesthetics in all-ceramic restorations. J Craniofac Surg 2010;21:2007-2012.

16. Chu FC, Chow TW, Chai J. Contrast ratios and masking ability of three types of ceramic veneers. J Prosthet Dent. 2007; 98:359-64.

17. Mokhtarpour H, Eftekhar Ashtiani R, Mahshid M, Tabatabaian F, Alikhasi M. Effect of screw access hole preparation on fracture load of implant-supported zirconia-based crowns: an in vitro study. J Dent Res Dent Clin Dent Prospects. 2016; 10:181-8. doi: 10.15171/joddd.2016.029.

18. Vichi A, Louca C, Corciolani G, Ferrari M. Color related to ceramic and zirconia restorations: a review. Dent Mater. 2011; 27:97-108.doi:10.1016/j.dental.2010.10.018.

19. Vichi A, Ferrari M, Davidson CL. Color and opacity variations in three different resin-based composite products after water aging. Dent Mater 2004;20:530-534.

20. Douglas RD, Steinhauer TJ, Wee AG. Intraoral determination of the tolerance of dentists for perceptibility and acceptability of shade mismatch. J Prosthet Dent 2007;97:200-208.
21. Lindsey DT, Wee AG: Perceptibility and acceptability of CIELAB color differences in computer-simulated teeth. J Dent 2007;35:593-599.

22. Ishikawa-Nagai S, Yoshida A, Sakai M, et al. Clinical evaluation of perceptibility of color differences between natural teeth and all-ceramic crowns. J Dent 2009;37(Suppl. 1):e57-63.

23. Ghinea R, Perez MM, Herrera LJ, et al. Colour difference thresholds in dental ceramics. J Dent 2010;38(Suppl 2):e57-64.

24. Lee YK, Lim BS, Kim CW. Difference in polymerization color changes of dental resin composites by the measuring aperture size. J Biomed Mater Res B Appl Biomater 2003;66:373-378.

25. Paravina RD, Ontiveros JC, Powers JM: Curing-dependent changes in color and translucency parameter of composite bleach shades. J Esthet Restor Dent 2002;14:158-166.

26. Yu B, Lee YK. Differences in color, translucency and fluorescence between flowable and universal resin composites. J Dent 2008;36:840-846.

27. Kim IJ, Lee YK. Changes in color and color parameters of dental resin composites after polymerization. J Biomed Mater Res B Appl Biomater 2007;80:541-546.

28. Kim BJ, Yu B, Lee YK: Shade distribution of indirect resin composites compared with a shade guide. J Dent 2008;36:1054-1060.

29. Douglas RD, Brewer JD: Acceptability of shade differences in metal ceramic crowns. J Prosthet Dent 1998;79:254-260.

30. Powers JM. Restorative dental materials. 14th ed. St. Louis: Mosby; 2018. p. 53.

31. Del Mar Pérez M, Ghinea R, Ugarte-Alván LI, Pulgar R, Paravina RD. Color and translucency in silorane-based resin composite compared to universal and nanofilled composites. J Dent 2010;38(S):e110-6.

32. Johnston WM, Ma T, Kienle BH. Translucency parameter of colorants for maxillofacial prostheses. Int J Prosthodont 1995;8:79-86.

33. Yang D, Raj R, Conrad H. Enhanced sintering rate of Zirconia (3Y-TZP) through the effect of a weak dc electric field on grain growth. J Am Ceram Soc 2010; 93: 2935-7.

34. Li JF, Watanabe R. Phase Transformation in Y2O3-Partially-Stabilized ZrO2 Polycrystals of Various Grain Sizes during Low-Temperature Aging in Water. J Am Ceram Soc 1998; 81: 2687-91. 
35. Casolco SR, Xu J, Garay JE. Transparent/translucent polycrystalline nanostructure yttrium stabilized zirconia with varying colors. Scr Mater 2008; 58: 516-9.

36. Jiang L, Liao Y, Wan Q, Li W. Effects of sintering temperature and particle size on the translucency of zirconium dioxide dental ceramic. J Mater Sci 2011; 22: 2429-35.

37. Anselmi-Tamburini U, Woolman JN, Munir ZA. Transparent nanometric cubic and tetragonal zirconia obtained by high-pressure pulsed electric current sintering. Adv Funct Mater 2007; 17: 3267- 73.

38. Alaniz JE, Perez-Gutierrez FG, Aguilar G, Garay JE. Optical proprieties of transparent nano crystalline yttrium stabilised zirconia. Opt Mater 2009; 32: 62-8.

39. Zhang Y, Kim JW. Graded structures for damage resistant and aesthetic all-ceramic restorations. Dent Mater 2009;25:781-90.

40. Maerten A, Zaslansky P, Mochales C, Traykova T, Mueller WD, Fratzl P, et al. Characterizing the transformation near indents and cracks in clinically used dental yttria- stabilized zirconium oxide constructs. Dent Mater 2013;29: 241-51.

41. López-Suárez C, Castillo-Oyagüe R, Rodríguez-Alonso V, Lynch CD, Suárez-García MJ. Fracture load of metal-ceramic, monolithic, and bi-layered zircônia-based posterior fixed dental prosthesis after thermo-mechanical cycling. J Dent 2018;73:97-104.

42. Griffin, J.D. Combining monolithic zirconia crowns, digital impressioning, and regenerative cement for a predictable restorative alternative to PFM. Compend. Contin. Educ. Dent. 2013, 34, 212-222. [PubMed].

43. Tong, H.; Tanaka, C.B.; Kaizer, M.R.; Zhang, Y. Characterization of three commercial Y-TZP ceramics produced for their High-Translucency, High-Strength and High-Surface Area. Ceram. Int. 2016, 42, 1077-1085. [CrossRef] [PubMed].

44. Zhang, Y. Making yttria-stabilized tetragonal zirconia translucent. Dent. Mater. 2014, 30, 1195-1203. [CrossRef] [PubMed]

45. Zhang, F.; Vanmeensel, K.; Batuk, M.; Hadermann, J.; Inokoshi, M.; Van Meerbeek, B.; Naert, I.; Vleugels, J. Highly-translucent, strong and aging-resistant 3 Y-TZP ceramics for dental restoration by grain boundary segregation. Acta Biomater. 2015, 16, 215-222. [CrossRef].
46. Zhang, Y.; Lawn, B.R. Novel Zirconia Materials in Dentistry. J. Dent. Res. 2018, 97, 140-147. [CrossRef] [PubMed].

47. Cho Y-E, Lim Y-J, Han J-S, Yeo I-SL, Yoon H-I. Effect of Yttria Content on the Translucency and Masking Ability of Yttria-Stabilized Tetragonal Zirconia Polycrystal. Materials. 2020; 13(21):4726. https://doi.org/10.3390/ ma13214726.

48. Putra, A.; Chung, K.-H.; Flinn, B.D.; Kuykendall, T.; Zheng, C.; Harada, K.; Raigrodski, A.J. Effect of hydrothermal treatment on light transmission of translucent zirconias. J. Prosthet. Dent. 2017, 118, 422-429. [CrossRef]

49. Harada, K.; Shinya, A.; Gomi, H.; Hatano, Y.; Shinya, A.; Raigrodski, A.J. Effect of accelerated aging on the fracture toughness of zirconias. J. Prosthet. Dent. 2016, 115, 215-223. [CrossRef].

50. Nakamura T, Saito O, Fuyikawa J, Ishigaki S. Influence of abutment substrate and ceramic thickness on the colour of heat-pressed ceramic crowns. J Oral Rehabil. 2002;29:805-9.

51. Shimada K, Nakazawa M, Kakehashi Y, Matsumura H. Influence of abutment materials on the resultant color of heat-pressed lithium disilicate ceramics. Dent Mater J. 2006;25:20-5.

52. Paravina RD, Ghinea R, Herrera LJ, Bona AD, Igiel C, Linninger $\mathrm{M}$, et al. Color difference thresholds in dentistry. J Esthet Restor Dent 2015;27 Suppl 1:S1-9.

53. Khashayar G, Bain PA, Salari S, et al. Perceptibility and acceptability thresholds for colour differences in dentistry. J Dent 2014;42:637-644.

54. Galip Gurel. The Science and Art of Porcelain Laminate Veneers. Quintessence Publishing. Germany, 2003, pp.159-204.

55. Tabatabaian F, Shabani S, Namdari M, Sadeghpour K. Masking ability of a zirconia ceramic on composite resin substrate shades. Dent Res J (Isfahan). 2017 NovDec;14(6):389-394.

56. Suputtamongkol K, Tulapornchai C, MamaniJ, KamchatphaiW, Thongpun N. Effect of the shades of background substructures on the overall color of zirconia-based allceramic crowns. JAdv Prosthodont 2013;5:319-25. 